\title{
CONSCIOUSNESS, SELF-CONSCIOUSNESS, AND AUTHORITATIVE SELF-KNOWLEDGE
}

\author{
CYNTHIA MACDONALD
}

\begin{abstract}
Many recent discussions of self-consciousness and self-knowledge assume that there are only two kinds of accounts available to be taken on the relation between the so-called first-order (conscious) states and subjects' awareness or knowledge of them: a same-order, or reflexive view, on the one hand, or a higher-order one, on the other. I maintain that there is a third kind of view that is distinctively different from these two options. The view is important because it can accommodate and make intelligible certain cases of authoritative self-knowledge that cannot easily be made intelligible, if at all, by these other two types of accounts. My aim in this paper is to defend this view against those who maintain that a same-order view is sufficient to account for authoritative self-knowledge.
\end{abstract}

A prevailing assumption in some recent discussions of self-consciousness and of self-knowledge is that there are really only two kinds of views that can be taken about subjects' awareness or knowledge of their own conscious intentional or phenomenal states (Thomasson 2000; Kriegel 2003a, 2003b, 2006). Either one can take a kind of 'same-order', or 'one-level', view about the relation between such states and subjects' awareness or knowledge of them (Block 2007; Burge 1996, 1998, 2007) $)^{1}$ or one can take a kind of 'higher-order' view, according to which a necessary condition on one's being in a conscious intentional or phenomenal state is that one has a distinct, 'higher-order' perception or thought about it (Armstrong I98I, I984; Lycan I987, I996; Rosenthal I986, I997, 2005). ${ }^{2}$

I think, however, that there is a third kind of view that is distinc-

\footnotetext{
${ }^{1}$ Block (2007) also mentions the possibility of taking a kind of deflationary 'automatic' view of the sort held by Sosa (2003).

${ }^{2}$ There are other types of higher-order views, for example the extension-determination view (Wright 1986, I988, I992), as well as views that fall outside the same-order/higher-order classification category altogether, such as some types of agency views (McGeer I996), neoexpressivist ones (Bar-On 2004), and more deflationary ones, such as the 'automatic' view mentioned in n. I. For the purposes of this discussion, however, I restrict myself to views of these two types.
} 
tively different from these two commonly assumed options, one I shall call 'second-order' to distinguish it from the kind of higher-order view just mentioned. This view is important because it can accommodate and make intelligible certain cases of authoritative selfknowledge that cannot easily be made intelligible, if at all, by the other two types of accounts on offer. ${ }^{3}$ These cases are themselves important because they are central to human reasoning and rationality. My aim is to set out this view and provide a partial defence of it.

Many higher-order views take an introspectionist form, and it is in this context that I will conduct my discussion, since the account I myself favour is introspectionist. ${ }^{4}$ Though it is designed to account for authoritative self-knowledge of one's conscious intentional states, I believe that it can be extended to account for knowledge of one's conscious phenomenal states. A thoroughgoing defence of the type of account that I think is needed would motivate it against both of the two types of views described above. However, my aim here is the more limited one of motivating the second-order view on which my account relies only against those who think that some kind of sameorder view is sufficient to account for authoritative self-knowledge.

Despite this limitation, my discussion impinges on recent work on introspective awareness of one's phenomenal states by those such as Block, who, for some time now, has been defending the claim that there is a distinction in kind to be drawn between phenomenal and access consciousness (Block I995, 2003, 2005, 2007). According to him, for a psychological state to be phenomenally conscious is for there to be something it is like for a subject to be in it. Such a state has experiential properties, properties that are 'what it is like' to be in it. But it also has a kind of 'me-ishness': being in such a state requires a subject's being aware of it in some sense. ${ }^{5}$ For a psychologi-

\footnotetext{
${ }^{3}$ By 'self-knowledge' I mean a subject's knowledge of her own mental (intentional and other) states. This contrasts with another use of the term to apply to knowledge of the subject of mental states, or the self, and its nature (see, for instance, Shoemaker I968; Evans I982; Bermudez I998). This use will not form part of my discussion.

${ }^{4}$ See, for example, Lycan (1987, 1996).

${ }^{5}$ As Block puts it,

We may suppose that it is platitudinous that when one has a phenomenally conscious experience, one is in some way aware of having it. Let us call the fact stated by this claim - without committing ourselves on what exactly that fact is - the fact that phenomenal consciousness requires Awareness. ... Sometimes people say Awareness is a matter of having a state whose content is in some sense 'presented' to the self or having a state that is 'for me' or that comes with a sense of ownership or that has 'me-ishness' .... (Block 2007, p. 484)
} 
cal state to be access conscious is for it to be cognitively accessible, which, for Block, is for it to be '(I) inferentially promiscuous, i.e., poised to be used as a premiss in reasoning, (2) poised for control of action, and (3) poised for rational control of speech' (Block I995, p. 230). ${ }^{6}$ In his 2003 and 2005 , Block's claim was that phenomenology and cognitive accessibility are wholly distinct. More recently, however, he has defended a weaker version of the claim, namely, that phenomenal consciousness 'outstrips' or overflows access consciousness, by which he means that cognitive accessibility is not constitutively connected to, and so required for, phenomenal consciousness (Block 2007). He further argues that recent work on the neural correlates of consciousness supports this view.

Block's argument makes use of a 'same-order', or 'reflexive' model of self-awareness (or awareness of one's own phenomenally conscious states) favoured by those such as Tyler Burge, according to which '... the consciousness-of relation can hold between a token experience and itself. A conscious experience is reflexive in that it consists in part in an awareness of itself' (Block 2007, p. 8), ${ }^{7}$ and this is where my discussion impinges on his view. My proposal opens up a way of marking a distinction between certain cases of phenomenal self-awareness, what might be called 'intransitive' ones, which Block claims do not require attention, and others, where attention is involved. ${ }^{8}$ Further, if, as some argue, these latter cases of self-awareness require conceptualization of the specific phenomenal contents of one's own phenomenal states, my proposal can help to

${ }^{6}$ Though he does not take the third condition to be a necessary one. Block's notion of cognitive accessibility is a dispositional one, and Burge (2007) has argued that this is not sufficient for cognitive accessibility; that for a state to be cognitively accessible it must actually be manifested, or occurrent.

${ }^{7}$ His claim about the same-order view explicitly concerns only phenomenally conscious states of the sort that (he claims) do not require attention and so cognitive accessibility:

... the fact of Awareness [i.e. awareness-access, in contrast with cognitive access] can be accommodated by either the same-order view or the view in which Awareness is automatic, or so I will assume. So there is no need to postulate that phenomenal consciousness requires cognitive accessibility of the phenomenally conscious state. Something worth calling accessibility may be intrinsic to any phenomenally conscious state, but it is not the cognitive accessibility that underlies reporting. (Block 2007, p. 485)

${ }^{8}$ There are some terminological points that need to be noted here. Block does not claim that his appeal to a same order view is to an 'intransitive' view of Awareness (awareness of one's phenomenal states which is not accompanied by cognitive accessibility); in fact he pretty much denies this, saying 'Burge ... distinguishes between phenomenality - which he is uncomfortable about calling a kind of "consciousness" - and phenomenal consciousness which is phenomenality that is the subject of some kind of access', and adds:

Burge argues that there is a kind of primitive of-ness of a phenomenally conscious state 
explain why such awareness might constitute authoritative selfknowledge and why introspective reports might have, as Block claims, a fallible and defeasible status, compatibly with this.

that is not reducible to higher order thought (and not reducible to any other cognitive notion). ... I argue that 'phenomenal consciousness' in my sense of the term can be either transitive (take an object of which the subject is conscious) or intransitive. My intransitive phenomenal consciousness corresponds to Burge's phenomenality, and my transitive phenomenal consciousness corresponds to Burge's phenomenal consciousness. (Block 2005, longer version, p. 9, n.9)

Block also claims that phenomenal consciousness is not to be identified with intransitivity, since there are transitive as well as intransitive cases of phenomenally conscious states. As an example of the former he mentions one's perceptual state of seeing a square; it has a phenomenally conscious content (what seems to be what Burge calls phenomenality) that represents a square, and so is a state of one's being phenomenally conscious of a square. While I agree that there are both transitive and intransitive cases of phenomenal consciousness (in both the creature and the state sense), I am concentrating specifically on self-, or subject-awareness of one's conscious states rather than on one's phenomenal awareness of what those states represent. That, on the same order view, phenomenally conscious states have a kind of primitive 'of-ness' does not thereby make a subject's awareness of them transitive, since I take it that the relevant transitivity here involves taking the phenomenally conscious state itself to be an object of self-awareness, and Burge himself, though 'tempted' by the transitive view, denies that the relation that a subject bears to her states in cases of subject-awareness is of the act-object kind, which the transitive view suggests. That is to say, although he treats phenomenally conscious states as involving a relation, that of being 'conscious for', or 'presented to', a subject, and he takes a same-order view of a subject's awareness of them, he is not inclined to treat that relation transitively in the act-object way. Thus, he says,

Sensing and phenomenal consciousness are not themselves acts. The aspects of phenomenal states that are phenomenally conscious for an individual are not objects, in the most commonsense uses of the term. They are not objects of perception. They are not objects of reference, at least not by virtue of being phenomenally conscious. And they are not individuals. They are aspects, aspect instances, of psychological states. Psychological states are states of individuals. (Burge 2007, p. 404)

My appeal in $\$ 2$ of the text to the transitive-intransitive distinction is not designed to mark a distinction between access and phenomenal consciousness (which attempt Block argues is misguided), but rather to help mark an intuitive distinction between awareness or knowledge of one's own conscious states, where these are taken to be distinct from and causally related to one's awareness or knowledge of them, and awareness or knowledge of one's own conscious states, where this is understood in terms of the same-order view. Kriegel $(2003 a)$ and Zahavi (2006), amongst others, take phenomenally conscious states (understood in the same-order way) to be cases of intransitive consciousness because awareness of them is not of states that are distinct from and causally related to the awareness of them. Such states of phenomenal consciousness are intrinsically about themselves. 
Direct Epistemic Access and Authority. Introspectionist accounts of self-knowledge are motivated by the apparent need to account for a number of striking features of at least some such knowledge, which ordinary empirical knowledge, including knowledge of the mental states of others, is typically thought to lack. Knowledge of certain of one's mental states is said to be epistemically direct or immediate in some sense (for example, in being non-inferential and/or nonevidence-based), and so privileged and/or authoritative (perhaps in being incorrigible, or infallible, or transparent to oneself, or all three of these). Introspectionist accounts attempt to account for some or all of these features by reference to a special method by which this knowledge is obtained.

The account of authoritative self-knowledge that I favour is designed to handle a certain class of cases, ones in which a subject is consciously both thinking and thinking about a current thought (the so-called cogito-type cases (Burge I988, I996, I998)), which extends beyond those cases explicitly countenanced by Burge and others (e.g. Davidson 1984a, 1987, I989). Theirs are ones in which subjects are claimed to be authoritative because their thoughts about their own thoughts are contextually self-verifying, the socalled second-order thoughts literally containing as constituents the first-order ones. This view is referred to as the 'same-order' or 'reflexive' view.' While I do not deny it, I want to extend the class to include cases that need to be handled differently, for two reasons. First, I think it plausible that there are many cases of self-knowledge where subjects are authoritative but not infallible, where such knowledge is a genuine cognitive achievement, something subjects can strive for but fail to possess. Indeed, these are arguably the most interesting cases of authoritative self-knowledge. This achievement

\footnotetext{
${ }^{9}$ There are different versions of what goes under the name of a 'same-order' or 'same-level' view. One version, which is often attributed to Brentano (I 874), has it that there is a single state (in this case a state of awareness of one's own conscious state) which is intentionally directed upon itself. Kriegel interprets this as a view according to which

The subjective character, or for-me-ness, of an experience consists ... in the inner awareness the experience involves. Now, awareness of something involves intentional directedness towards it. So for a mental state to have inner awareness built into it, it must be intentionally directed at itself. When a mental state is intentionally directed at itself, it is both intentional act and intentional object. (Kriegel 2005, p. 29)
}

Other versions have been held by Husserl (I928), Kriegel (2006), Smith (1986, I989 ch. 2), Thomasson (2000), and Zahavi (I998, 2006). 
needs explaining, and a different epistemology of self-knowledge is called for in these cases. Second, and relatedly, authority comes in degrees, so any account of it should be capable of being generalized to cases other than those in the limited class targeted by the sameorder or reflexive view.

My account does not deny that there are instances of authoritative self-knowledge that fit the same-order view. On the contrary, it exploits the fact that there are. However, the cases that are of interest to me are ones that are best construed as involving not one, but two conscious states, both in what is sometimes called the specious present, one of which is causally as well as conceptually related to the other. It is a moot point whether one is prepared to call these 'cogito-type' cases; I am, as they involve a kind of temporal immediacy between the relevant states in which the state reflected upon is presented as present, and it is this that warrants the use of the term. Those who disagree can view my account as an attempt to give an account of authoritative self-knowledge for intentional statesstates with intentional content of the form ' $S \phi s$ that $p$ ' (for some subject $S$, attitude $\phi$, and propositional content $p$ ), where the states in question are either current, conscious thoughts or states that either overlap temporally or are temporally 'adjacent' in the so-called specious present, involving no long-term memory.

This account of the relation between first-order and second-order thoughts in the cogito-type cases better explains the authoritative nature of self-knowledge in such cases than the kind of account given by those such as Davidson and Burge. ${ }^{10}$ One reason is that, on that latter type of account, authoritative self-knowledge is infallible, cogito-type thoughts being contextually self-verifying. It cannot handle cases of authoritative self-knowledge that intuition tells us are ones in which subjects are better placed to know but are not infallible about their own mental states. The account I am recommending gives the notion of direct epistemic access some real work to do, and in so doing, displays authoritative self-knowledge as a genuine cognitive achievement, something that subjects can strive for but fail to possess.

Further, it opens up the possibility of giving an account of authoritative self-knowledge that can be generalized beyond the cogitotype cases, where the relevant first-order thoughts are ones that a subject is currently, consciously thinking, to cases involving phe-

${ }^{10}$ See Davidson (I984a, I987, I989) and Burge (I996, I998). See also Heil (I988, I992). 
nomenally conscious states such as perceptual experiences, sensations, and memory experiences in which a subject aims to identify a past thought by trying to think a content that is partly of the same type as that of the past thought.

The cogito-type cases are particularly interesting ones on which to focus attention for two reasons. First, they are arguably the most plausible examples of authoritative self-knowledge, and it is knowledge of this sort that is especially difficult to explain. The reason is that subjects' knowledge of what they are currently, consciously thinking is typically not based on evidence, and beliefs that are not based on evidence are not generally thought to be more reliable than ones that are. ${ }^{11}$ But the non-evidence-based character of cogito-type thoughts seems actually to place subjects in a better position than others to know what thoughts they are currently, consciously thinking.

Second, the cogito-type cases are ones in which a subject is reflecting on a thought about which she is conscious. Not only is the thought reflected upon a conscious thought; but it is a thought about which that subject is consciously aware. These cases thus provide us with the best possible examples of thoughts concerning which one might have a sort of 'inner' awareness.

My account begins with the thought that a subject's awareness of her own current, consciously entertained thoughts is peculiarly direct in being non-evidence-based, non-inferential, and unmediated by some further intentional (or sensational) state. ${ }^{12}$ I call this kind of

\footnotetext{
11 'Generally' here marks a contrast between self-knowledge and the more typical cases of knowledge of the external world. If, for example, I believe that there's an apple before me on the basis of no evidence and you believe that there's an apple before me on the basis of looking in my direction, it's reasonable to suppose that your belief is more likely to be reliable than mine. But if I think I believe that there's an apple before me on the basis of no evidence and you think I believe that there's an apple before me on the basis of my behaviour, it's reasonable to suppose that my thought is more likely to be reliable than yours. Some, like Heil (I988, I992), emphasize the non-empirically-evidence-based character of certain selfknowledge, whereas others, like Wright (1989), take such knowledge to be non-evidencebased tout court. Alston (I97I) gives an illuminating account of the different senses that might attach to the notion of direct or immediate access. He argues that the notion of directness that is relevant to self-knowledge is epistemic, not causal, and is explicable in terms of being non-evidence-based, where this is distinct from being non-inferential. In a similar vein, Gertler (2003) distinguishes two senses of 'direct' in 'direct access', one epistemic (what Alston characterizes as 'non-inferential') and the other metaphysical (which she characterizes as 'unmediated'). The core of my account of authoritative self-knowledge relies on both of these senses of direct and immediate access, though I think it is misleading to call the second 'metaphysical'. For more on it see Macdonald (1998a, I998b, forthcoming).

${ }^{12}$ Note that I do not here mean that such knowledge is baseless. If it were, there would be no need for an epistemology of self-knowledge, no need for an account of the kind that is here being offered. For more on this see Wright (I998) and McDowell (I998).
} 
directness epistemic directness, and the awareness associated with it direct epistemic access. My proposal is that there are certain features of properties to which subjects have direct epistemic access that mark them off from other sorts of properties to which subjects do not typically have direct epistemic access. One has to do with knowledge of objects: such properties are epistemically basic in that they are the fundamental and favoured means by which knowledge of the objects that have them is obtained; in getting to know what an object is, these are the first of its properties that one comes to know that it has. Another has to do with the properties themselves: they typically are as they appear to be to normal subjects in normal circumstances; they are epistemically direct or immediate.

These two epistemic features are possessed by properties that fall into the broad category of observable ones, specifically, the so-called primary qualities such as being square, and secondary qualities, such as being red, of objects of perceptual experience. It is also plausible to suppose that they are possessed by contentful intentional properties of first-order states when these are currently, consciously entertained and reflected upon while thinking them.

Consider, first, properties other than contentful intentional ones where the notion of direct epistemic access is generally thought to apply. I know that the apple visually present before me is red, and that it is round, and this knowledge is plausibly understood as being direct (although not baseless). One aspect of this epistemic directness has to do with the fact that my knowledge is arrived at by means of properties that are epistemically basic. They are epistemically basic because they are the fundamental and favoured means by which my knowledge of the apple is obtained. What makes them epistemically basic is that my access to them is non-inferential, and more generally, non-evidence-based. I can know directly that the apple is an instance of this particular shape property, or an instance of this particular colour property, because the instance is presented to me as an instance of that property through my sense of sight. I perceive the instance as an instance of that property, and so no evidence is needed to come to know that it is an instance of that property. ${ }^{13}$

\footnotetext{
${ }^{13}$ So, the notion of being non-evidence-based of interest here goes beyond that of being nonempirically-evidence-based. My proposal is that the notion of 'seeing as' that is in play with respect to observable properties in perception is factive-one cannot, for example, see $a$ as $F$ without seeing $a$. So, one cannot see an instance of red $a$ s an instance of red without seeing that instance (Kvart I 993). Further, the notion of seeing that is in play is that of epistemic
} 
This is not true of other properties of the apple. It is, for example an instance of a certain chemical-structure property (and an instance of a certain mass property), but this instance is not manifested to me as an instance of that property through one of my senses. Similarly, water is both an instance of wetness and an instance of the chemical structure property, $\mathrm{H}_{2} \mathrm{O}$, but although the instance of wetness is manifested to me as an instance of wetness, through my sense of touch, the instance of ' $\mathrm{H}_{2} \mathrm{O}$-ness' is not manifested to me as an instance of that property through one of my senses. In short, certain properties seem to be ones to which we have direct epistemic access in part because they are observable: whether objects are instances of them can be determined just by unaided observation of those objects. ${ }^{14}$

Consider now contentful properties, properties of contentful intentional states. When one thinks of a first-order intentional state, say, a thought that water is transparent, while undergoing, or think-

seeing (to use Dretske's distinction, though not his view of perception). According to this, to see a particular item (an individual object, an instance of redness) is to see it as an instance of some property $F$. Seeing is epistemic in the sense that, when a subject has such a perceptual experience, she takes an object $a$ to have some property or other. She does so because the content of her experience represents the world around her as being some way or other.

To accept a view like this is not necessarily to deny that there is much that we see that we do not take ourselves to see. But it is to deny that the idea that in perception we do not take an object $X$ to be any way at all is a genuine possibility. As Heil puts the point,

$\ldots$ it is easy to imagine cases in which, for any given property, $P$, possessed by $X, S$ sees $X$ without taking $\mathrm{X}$ to have $P$. And we might describe such cases as ones in which $S$ fails to see $X$ under a certain aspect. On the other hand, the plausibility of these cases may well rest at least in part on the tacit assumption that $X$, if not seen under this aspect, is seen under some other aspect, if not taken to have $P$, then taken to have some other property, $P^{\prime}$... [S]eeing tout court requires that there be cases in which $S$ encounters $X$ perceptually, but does not take $X$ to be any way at all. It is far from clear, however, that there are any such cases ... (Heil I99I, p. 8)

Heil's claim is that whatever 'perceptual experience' is, for human beings anyway, it is doubtful that it is completely unconceptualized, 'nonepistemic' perception. For further discussion of this, see Macdonald (2002). So, the objection that seeing an instance as an instance of brown is evidence-based because it is based on seeing brownness misunderstands the epistemic situation. To see an instance of brown as an instance of brown just is what it is to see brownness.

${ }^{14}$ The distinction I am after can be captured by means of the distinction between seeing $x$ and seeing that $p$. Given this distinction, I can both see that the apple is red and see the apple's redness; but although I can see that the liquid before me is $\mathrm{H}_{2} \mathrm{O}$, I cannot see its ' $\mathrm{H}_{2} \mathrm{O}$-ness'. Only the former counts as a case of direct epistemic access. For discussion of observable properties and predicates, see Wright (I987). See also Peacocke (I983) for discussion of conditions necessary and sufficient for a concept to be observational. Peacocke further elaborates the sense in which the two features I take here to be central to a property's being observable are features of observational concepts. 
ing it, from the point of view of a second-order intentional state, one's grasp of that first-order state is first and foremost a grasp of it as a state of a certain contentful type, as, say, a thought that water is transparent. One grasps the state as an instance of a certain contentful type, and no evidence is needed to come to know that it is an instance of that contentful type. The point is not that that state cannot be known by means of other properties (intentional or non-intentional); it is not that I cannot think of that state apart from thinking of it as a state of a contentful type. (If, for example, physicalism is true, and mental states just are physical ones, then they can be known by means of their non-intentional physical properties.) It is that, in thinking about a first-order intentional state of mine while thinking it, I typically grasp it first and foremost as a state of a given contentful type.

Consider, now, the second feature, that such properties are in general as they appear to be to their subjects; they are epistemically direct. I think that this feature also applies to intentional properties in the cogito-type cases. The reason, for which I argue elsewhere, is that the relation between contentful properties and awareness of them by normal subjects in normal circumstances in these cases is in critical respects relevantly like secondary qualities and experiences of them by normal perceivers in normal circumstances, on a certain view of the nature of such properties (namely, a primitivist one) (Macdonald I998a, I998b, forthcoming).

If, when one is both currently, consciously thinking and thinking about one's own intentional states, one grasps those states first and foremost as instances of contentful intentional properties (i.e., such properties are epistemically basic) and such properties are in general as they appear to be (i.e., are epistemically direct or immediate), and if subjects are the only ones to whom their contentful properties appear in the epistemically basic and direct way, it follows that, in general, in these cases, subjects have authoritative knowledge of these contents. However, a number of points need to be made about this argument and the account of direct epistemic access on which it is based.

First, the argument moves from claims about epistemic basicness and epistemic directness or immediacy and a claim about privileged access to a conclusion about authoritativeness. The claim that no one other than $S$ is the subject of $S$ 's intentional states is one about differential access - that the way in which one can come to know 
one's own states is different from the way in which others can come to know them. The claim that $S$ is the only one to whom her contentful states can appear in the epistemically basic and direct way is one about privileged access - that one is better placed than others to know the contents of one's own intentional states. The conclusion, that $S$ is authoritative with regard to the contents of her own intentional states, follows precisely because $S$ has privileged access to those contents. But one can be authoritative without having privileged access; so the notion of authority is more general than that of privileged access. One might, for example, be more authoritative than others in one's knowledge of the chemical constitution of things because one has taken a degree in Chemistry. But this authority is not due to one's access to Chemistry being privileged in any significant sense. Similarly, one's authority with respect to the colour of the chair in a room in which one happens to be the only occupant is not in any significant way due to one's access being privileged. In the case of authoritative self-knowledge of the contents of one's own intentional states, privileged access is secured by the fact that no one other than the subject can have direct epistemic access to them given that she alone is the subject of her own intentional states.

Second, others can have epistemic access to my states. However, their access is evidence-based. This asymmetry is what explains the asymmetry between self-knowledge and knowledge of others that is symptomatic of first-person authority. Correlatively, when I know my states in this evidence-based way, there is no first-person authority for me.

Third, when I think about my first-order intentional states in an epistemically direct or immediate way, I authoritatively know the contents of my first-order (reviewed) states because I am better placed than others to know them, but my knowledge is neither incorrigible nor infallible. Because, when reflecting on such a thought, the thought on which I am reflecting is distinct from and independent of the reflecting one, my thought about what I am currently, consciously thinking is not contextually self-verifying and my knowledge is not infallible. And my claim to know what I am thinking is defeasible: others, who know my thoughts in an evidencebased way, may sometimes for this reason be in a position to show me that I am mistaken about what I am in fact thinking.

Further, one's authority in the kinds of cases under discussion 
here is explained as consisting in the fact that one is better placed in reflection to correctly identify the objects of one's reflection (i.e., the contents of one's first-order states), and this is so because, when successful, the content of the reflecting thought is determined by that of the one reflected upon. Reflection is, in one respect at least, an appropriate characterization of the relation which subjects' second-order thoughts bear to their first-order ones in these cases. In physical reflection-say, in a mirror-under normal conditions (which include normal observers), the object will not be misrepresented. So the object is as it appears to be. But the reflection does not determine the object to be what it is. Similarly, in mental reflection, when successful, what is thought or reflected upon determines the content of the reflection. ${ }^{15}$

On this way of viewing things, when one thinks about a current, conscious, first-order intentional state by thinking a second-order state that is token-distinct from it, one does so by thinking a content that is partly of same type as that tokened in the first-order intentional state. When successful, the content of the reflective thought has, and presents itself as having, a constituent of the same type as that which forms the content of the thought reflected upon (i.e., the subject thinks a token-distinct thought with part of the same content, she thinks that part again). Further, the content of the thought reflected upon is one to which the subject has direct epistemic access (i.e., it is epistemically basic and as it appears to the subject to be). Thus, although it is true that thinking such a second-order thought suffices for its being true, in a genuine case of reflection this is not because there is no first-order thought distinct from the reflective

\footnotetext{
$\overline{{ }^{15} \text { Moran (2005) considers the possibility that how a subject conceives of her first-order }}$ state (say, an emotion such as love) can change the state itself, alter it in significant ways, and that this can make an important difference to her other attitudes and behaviour. I do not deny that in reflection one can come to see one's own mental states in ways that were not apparent to one at another time, and that presenting those states in reflection in these new ways can make a difference to one's other attitudes and behaviour. But as Moran himself notes, this is not incompatible with a realist view of the nature of such states, which takes claims about them to be made true by facts about those states. Conceiving of one's own mental states in new ways may simply be a matter of discovering new properties of those states, in which case the states themselves are not thereby changed. Or one can come to see one's own states in ways that misrepresent them or are illusory. By this I mean: one can think a second-order thought with the content $I$ am thinking that $p$, aiming to target a distinct first-order state that I am also thinking $(p)$, in the specious present, and misrepresent the content of that first-order thought as $p$ when it is in fact $q$. In this case, although my second-order thought is contextually self-verifying, the content by which I think that thought fallibly represents, if at all, the content of my first-order thought.
} 
one to which it is causally as well as conceptually related.

Even in the cogito-type cases, however, success can come in degrees, and there can be partial failure in the attempt even to think a content that is partly of the same type as that tokened in a first-order thought. So self-knowledge, though authoritative, is corrigible as well as fallible. An example of one type of case where this may happen might be a situation in which I am daydreaming and suddenly become aware of this while continuing to fantasize. At the very point at which I become aware of it I might be able to capture in reflection some of the contents of my thoughts - say, that they involve a picnic - but not all - say, that Ian and Julia figure in these thoughts.

As the above sketch makes clear, the account I favour of introspective self-knowledge is a second-order rather than a same-order one. In $\$$ II I will explain in more detail the nature of this second-order view and it's relation to the same-order one. Finally, since one might deny that there is a need for any second-order view of the kind I am committed to, I revisit and defend this view in $\mathbb{S} \mathbb{S I I I}$ and IV.

Introspective Self-Knowledge of Phenomenally Conscious States. To see what kind of view I am advocating with respect to authoritative self-knowledge and how it contrasts with the reflexive, or same-order view, it may be helpful to position it in relation to another contrast with respect to subjects' awareness of their phenomenally conscious states within the nexus of distinctions between creature consciousness and state consciousness (Rosenthal I986, I997) and transitive and intransitive consciousness (Armstrong in Armstrong and Malcolm I984; Rosenthal 1986, I997). One reason why this might be of interest more generally is that considerations that can be seen to favour a kind of 'intransitive' view of phenomenal awareness do not rule out the applicability of a second-order view of certain kinds of cases of phenomenal awareness, notably ones involving attention. Many (including Block) agree that attention makes phenomenal states cognitively accessible, and this has important implications for any attempt to give a uniform account of selfknowledge of conscious phenomenal and intentional states, one that favours a second-order view of certain cogito-type cases of authoritative self-knowledge. 
One can attribute consciousness to organisms, such as people, and also to their psychological states. People can be conscious, in contrast with being unconscious, and their states can be conscious, or unconscious (as when, for example, one has a belief of which one is unaware). In the case of creature consciousness, one can be simply conscious (or conscious simpliciter), in the sense of being awake or being alert, or be conscious of something, where this is relational and takes an item as an object, where the object is typically viewed as distinct from and capable of existing independently of awareness of it. The former is what Rosenthal and Armstrong call 'intransitive' consciousness and the latter 'transitive' consciousness.

A state is intransitively conscious if it is conscious simpliciter, that is, if it is consciously present, present in consciousness. However, there is no obvious analogue of the transitive-intransitive distinction for state consciousness: conscious states are not themselves conscious of anything, so there is no analogue for states of creature transitive consciousness. One might, as a result, think that the distinction does not apply to state consciousness. But there is a way of formulating the distinction in terms that, on the face of it, do so apply. When I am conscious of the apple on my desk, I am in a certain mental state whose content represents the apple, and it is in virtue of being in this state that I am conscious of the apple. We can call the state in virtue of which I am conscious of the apple, where the apple is the object of my conscious state, a transitively conscious mental state (Kreigel 2004).

The distinction between state and creature consciousness can at any rate be recast as a distinction between first-order and secondorder creature consciousness. When I say that Sam's experience of an apple is conscious, it seems that on one interpretation this is the same as saying that Sam is consciously experiencing an apple. Whereas, in saying the former, however, I attribute a first-order property to Sam's experience, the property of being conscious, in saying the latter, I attribute a second-order property to Sam, the property of Sam's property of experiencing an apple. This way of recasting the distinction makes it possible to characterize intransitive state consciousness in a way that applies to creatures, this being desirable since phenomenally conscious states are typically thought to be such that there is something that it is like for a subject to be in them.

One way to understand the same-order view of the relation be- 
tween phenomenally conscious states and subjects' awareness of them is in terms of intransitive state consciousness recast in a way that applies to creatures, where a subject is intransitively conscious of her phenomenal state when she is consciously in, or experiencing, that state. ${ }^{16}$ Thus understood, when subjects are aware of their visual experiences, they are not aware of them in the robust sense that the states are objects of their awareness (not, at any rate, in the actobject kind of way that Burge (2007) associates with perception) rather, they are consciously visually experiencing objects presented to them perceptually. When subjects are in states that are phenomenally conscious in this sense, there is something that it is like for them to be in these states (Block I995a, 2007). Such awareness of one's experience, it is plausible to say, can be something that just happens, and does not require a subject to notice, attend to, or think about the experience itself. For this reason, it does not require a second-order view of the nature of the phenomenon, but only a less 'robust' same-order view (or an (even less robust) automatic, deflationary one). As Block himself puts the point,

... the kind of awareness I now say is a necessary part of conscious experience is not full-fledged self-awareness of the kind a rational thinking creature might sometimes have but a mouse will presumably not have. In I995, the only option I saw for explaining awareness-access in non-cognitive terms was as a kind of phenomenal property I called 'me-ishness'. But now I see that awareness-access [in contrast with cognitive access] can be adequately understood in terms of 'same-order' and deflationary theories, so there is no need for cognitive or other 'higher-order' accounts. (Block 2007, p. 536)

\footnotetext{
${ }^{16}$ Indeed, this is the way that Kriegel $(2005)$, cited by Block as holding the kind of sameorder view that he endorses, conceives of the same-order, or reflexive view. According to Kriegel, 'mental states which feature inner awareness are self-representing states, states which represent their very own occurrence. This is what constitutes the fact that they are the act of awareness and the object of awareness all at once' (Kriegel 2005, p. 38). Making use of the distinction between the content of a phenomenally conscious state and the mode in which it is had, or experienced, he adds,

Corresponding to this distinction between the content and the mode of experience is a distinction between two ways of trying to account for the self-directed intentionality of conscious experiences. Smith argues that this self-directedness is built into the mode of conscious experience. ... On this view, there is not only a difference between seeing a lion and fearing a lion, but also between awarely-seeing a lion and unawarely-seeing a lion. The difference is that awarely-seeing is seeing in a way that includes inner awareness of itself, whereas unawarely-seeing is seeing without such inner awareness. A conscious experience has subjective character in virtue of employing an intentional mode of a certain kind, the 'awarely' kind. (Kriegel 2005, p. 40)
} 
Block's reason for rejecting higher-order accounts is precisely that they require conceptualization of the specific contents of one's phenomenal experiences, and since second-order views also require this, it is likely that he would reject this kind of account also. As I said earlier, however, the kinds of cases of phenomenal awareness that a second-order view might be called upon to account for are plausibly ones involving attention, which Block agrees require conceptualization.

There is an analogue of this type of view of phenomenal consciousness in accounts of authoritative self-knowledge, as we've already seen. We can distinguish between such same-order views, such as that held by Burge, and others that are perhaps more deflationary (such as the 'view' held by McDowell (I986), according to which authoritative self-knowledge is the by-product of the minimal exercise of one's perceptual capacities), and more robust second-order views, such as the one I hold. Does the same-order view rule out the second-order one?

I think not. Again, we can see this more clearly with the help of the distinction between intransitive cognitive state awareness and a more robust view which takes the contents of cognitive states to be the objects of such awareness. My current, conscious thought that the apple on my desk is ripe is intransitively cognitively accessible if I am self-consciously thinking it. This sense of awareness does not require that we take the thought as its object, but only as its subject matter, where 'self-consciously' indicates the mode in which the thought is had. In thinking it, I am aware of thinking it, aware, in some sense, that thought is mine. This is a sense in which, say, I might be self- consciously thinking thoughts but not noticing or attending to them; although I am reasoning with them, and so am in some sense aware that I am having them, they are conscious for me, consciously present to me, I am not reasoning about them, and I am not reflecting on them.

Clearly, this kind of self-awareness does not require a secondorder view of the relation between the cognitive state and one's consciousness or awareness of it; a same-order, or even a more deflationary, view will do. But this kind of awareness does not preclude a more robust conception of 'self-awareness', or awareness of one's cognitive states (states such as my consciously thinking that the apple on my desk is ripe), where such awareness takes those states as objects. Although much reasoning merely makes use of conscious 
representational states - states with representational contents-in inference, planning, memory, and so on, at least some reasoning, notably critical reasoning, involves much more than just this. It involves attending to one's attitudes and contents in order to evaluate, accept or reject, or revise them in the light of others, and to bring about rational transitions between them. It is partly in virtue of having this ability to critically reason that human beings are held to be rationally responsible, rationally culpable, for their own reasons and reasoning, and rightly so. They must for this reason be presumed to be better placed than others to know their own conscious intentional states. My claim is that authoritative self-knowledge, the kind of self-knowledge that involves a subject's being better placed than others to know the contents of her own current conscious intentional states, requires, not merely self-consciously thinking them in the intransitive sense, nor thinking about them in the same-order sense, but attending to them, self-consciously thinking of or about them, while also self-consciously thinking them, in a transitive sense that requires a second-order view.

Burge (2007) maintains that noticing, attending to, thinking about one's own states in a way that meets the requirement of having 'rational control' over them need not require anything more robust than a same-order view. It may be that he intends a view that is more robust than the one presented here as a same-order view-as one according to which reflecting on one's first-order states just is reflectively thinking them, attending to them is attentively thinking them, and so on. But it does not involve anything as robust as the kind of second-order view I am recommending, since Burge rejects what I have called the transitive conception of the relation between conscious states and thoughts about them whereby such states are objects of awareness in the sense that they are distinct from and causally related to, thoughts about them. ${ }^{17}$ For him, and more obviously so for deflationists, authoritative self-knowledge, in the paradigmatic (cogito-type) cases, is not a genuine cognitive achievement, something subjects can strive for but fail to possess. It can be, and

\footnotetext{
${ }^{17}$ In the case of self-knowledge of one's own conscious intentional states, his reason is that if that conception were correct, the point of view or perspective of the reviewer could regularly 'come apart' from the perspective of the thought reviewed. And if this were to happen, the rational connection between one's thoughts and one's thoughts about those thoughts would be broken; one's thoughts could not give one immediate reason, from the point of the view of the reviewing thought, to adjust the thought reviewed. See Burge (1996, I998) and note 20 below.
} 
usually is, something that just happens. ${ }^{18}$ Although one can, and might be under an epistemic obligation to, give an explanation of it (which distinguishes the same-order from other more deflationary theories), that explanation need not invoke any more robust view than a same-order one. I do not think that this intransitive, sameorder, view can be all there is to an account of authoritative selfknowledge for the reasons I stated at the outset of my discussion. I think most cases of such authority involve subjects' being epistemically better placed than others to know the contents of their own first-order states, where this falls short of infallibility. So let me finish by trying to motivate the more robust, second-order view.

\section{III}

The Robust View. One might think that in cases of current, conscious thoughts, the root of one's so-called 'introspective' awareness is a kind of minimal self-consciousness of the sort described earlier as intransitive state self-consciousness. Suppose, for example, that I am driving home, aware that it is getting late, and trying to negotiate my way through the traffic so as to reach my destination by $6 \mathrm{pm}$. When I reach the shopping centre three blocks away from my home, I find myself pulling into the parking lot-and, asking myself why, become aware of the thought that has caused me to pull in, that it would be nice to have fish for dinner. This seems to be an example of a situation in which one's thought, though conscious and causally efficacious in bringing about one's behaviour, is not an object of attention, and when awareness of it does come to one, it does so in an unreflective sort of way. ${ }^{19}$ Another example is where one

\footnotetext{
${ }^{18}$ This is how Kriegel (2005) views intransitive self-awareness:

... intransitive self-cousciousness is effortless, in that in spite of it accompanying our conscious life permanently, it makes negligible demands on our cognitive resources. This is similar to the difference between, say, calculating and seeing: whereas the former requires an effort on one's part, the latter is effortless-it is something that just happens to one. (Kriegel $2003 a$, p. I05)

${ }^{19}$ Another well-worn example might be that of the long-distance truck driver, who arrives at his destination without having been consciously aware of what he has been doing and perceiving along the way (Armstrong I98I). Here it seems plausible to say (pace HigherOrder Theorists of consciousness) that the driver was undergoing conscious states in that he was perceptually conscious of things and phenomena around him, without yet being reflectively aware of the states he was undergoing because he was not attending to them. Armstrong draws a distinction between mere 'reflex' consciousness, the kind one might have when perceiving things in one's environment but not attending to (his term is 'scrutinizing')
} 
suddenly realizes the solution to a problem; the solution just 'comes' to one, and one is aware of this.

As I said earlier, I do not deny that there are many cases of such awareness, nor that this kind of awareness arguably constitutes the core of self-knowledge. Sometimes, however, subjects may be actively reflecting on the contents of their first-order thoughts in order to evaluate them. Critical reasoning seems to be one such case. Normally subjects engage in this process in order to make up their minds about what they are to think or believe. Further, the ability to engage in it requires being able to reflectively attend, in current, conscious thought, to one's own thought contents, and to know what those contents are, in order to accept, reject, or adjust those contents and effect rational transitions between them. And such a process takes time; it involves both thinking contentful thoughts and evaluating those thought contents and attitudes. This critical stance seems to involve thinking second-order thoughts about one's first-order ones, presenting those thoughts as present ones and thinking contents that present the contents of the first-order ones as the contents of the first-order ones, and so as candidates for endorsement, rejection, or revision in the light of other first-order contentful states. ${ }^{20}$ Thus, there seems to be, in reflection, an aspect of

them, and the kind of consciousness one has when attending to things in one's environment for a particular purpose one might have. Correspondingly, he notes, there is a difference between the kind of introspective awareness one has when one is in a state of the mere 'reflex' sort, and the kind one has when one is attending to one's own current state of mind.

${ }^{20}$ Burge argues that, in critical reasoning, self-knowledge must take a distinctive, non-observational (non-empirical) form. The reason has to do with the constitutive connection between one's judgements about one's thoughts and those judgements' being true (i.e., the constitutive connection between such judgements and their subject matter). If all of one's self-knowledge were observational, the connection between reflection and thought reflected upon would rest on a 'brute' (or 'unreasoning') contingency (a merely causal connection). Systematic error would be possible. But this is incompatible with the role that critical reasoning plays in guiding one's evaluations, adjustments, and corrections of reasons. That role requires that a single point of view be involved in critical reasoning, so that such reasoning is capable of giving the reviewer reason, from the point of view of the review, to adjust or correct the thought reviewed. If all of self-knowledge were like observation, agents would have an estranged perspective on their first-order thoughts; they wouldn't take facts about their first-order states to be directly relevant to their self-control and governance in immediately moving them to act. And if this were to happen, the rational connection between self-ascriptions and first-order thoughts wouldn't hold-the former would not give the agent direct reasons to change the latter. However, given the kind of second-order view I favour, involving reflective thoughts construed in the same-order way about one's firstorder ones, it does not follow that subjects would become estranged from their first-order thoughts. Further, critical reasoning requires both recognizing one's contents and attitudes as one's own and the capacity to take a detached view on those contents and attitudes in order to evaluate, revise, and reject them. 
the content of the second-order state itself (and not just the thinking of it) that is present, which is not present either when merely thinking the first-order thought or when simply becoming aware of it in a minimally (intransitively) self-conscious sort of way. This aspect is all the more obviously present in thoughts involving memory, where the aim is to recapture the content of a past intentional (or experiential) state. When I attempt to remember a past thought, the content by which I attempt to recapture the content of the past thought is one that presents the thought as past and its content as part of the content of that thought, and it is essential to its being a candidate for a genuine memory that this be so.

Critical reasoning must involve thoughts that are cogito-like, but if it involved only thoughts of the same-order, contextually self-verifying kind, this would not by itself suffice to provide assurance in particular cases where doubt arises about whether one is reasoning correctly or well, since this concerns the moves, the transitions, that a reasoner makes from one thought to another. Further, if critical reasoning involves thoughts of other kinds, thoughts about one's standing beliefs, for example, or about one's thoughts at an earlier time, then doubts of another kind can arise; doubts about whether one's judgements about one's own intentional states are even true. In both cases a worry about whether one has reasoned correctly arises, since a causal process connecting two thoughts is involved.

Suppose that I am sitting in a library, and am mentally evaluating an argument that I have been in the process of constructing in thought to reassure myself that it constitutes a decisive argument against a particular philosophical position. Not having written it down, I need first to try to identify the various contentful thoughts that I have been thinking. At various stages in the process, I doubt whether I have recaptured the right thought. I ask myself, have I been thinking that $p$ here in the argument, or is it that I have been thinking that $q$ ? Even if the thoughts I am having right now are ones that I know, and know infallibly because they are cogito-type thoughts in Burge's sense, the knowledge question that is pressing is whether these-contextually self-verifying-thoughts match the ones I've been thinking, and match them in the right order. And that question is left entirely open. So some situations in which questions concerning what I am currently consciously thinking arise cannot plausibly be viewed as conforming to the same-order view, but rather to a second-order one. 
There is also another process going on in this situation to consider, since I am not just running through a train of thought I've been thinking, trying to ensure that I am getting it right. I am doing so in order to come to a view about, to decide whether, that train of thought really does constitute an argument that is as decisive as I have been thinking it is. In thinking it through again, I am also evaluating it. I begin to doubt that it is decisive; in fact, I begin to doubt whether I have reasoned correctly at all. Will mere understanding of the thoughts I am having, and/or going through this process of reasoning now, suffice here to reassure me that I am indeed reasoning correctly? No, since I might be an inveterate affirmer of the consequent, or follower of counter-induction. Even supposing the process here to involve cogito-type thoughts of the contextually self-verifying, same-order kind, I cannot reassure myself just by knowing these reflective thoughts in virtue of understanding them, and by reasoning in the minimal sense associated with intransitive state selfknowledge, that I am reasoning correctly or well.

It may be that nothing could provide the kind of reassurance that is sought when doubt arises in the second stage of reasoning envisaged in this example. But the point is not that something could; it is that mere understanding and knowledge of one's thoughts when reasoning in particular cases, and mere understanding of one's own reasoning, is not sufficient to dispel doubts that arise in particular cases about whether one is reasoning correctly or well, even when those cases involve cogito-type thoughts understood in the contextually self-verifying, same-order way.

What about the kind of reassurance that is sought after when doubt arises in the first stage of reasoning envisaged in the above example? Here the problem is that the thoughts involved in the process of rethinking the original argument may or may not match the ones had at a prior stage during this interval of time, since this depends, at least in part, on the accuracy of my working memory.

These and many other cases seem to be ones in which it is plausible to say that a subject actively reflects on the content of her firstorder thought by thinking a distinct thought content in her secondorder thought that presents part of that content as the content of the first-order one. Such cases seem to involve what I earlier referred to as the specious present. Although it is controversial how to understand this phenomenon, one account has it that subjects experience events that are past, but so immediately so that they are experienced 
as present. $^{21}$ Another has it that subjects immediately experience change, or succession, during a period of time that is an interval (Dainton 2000). One familiar example often given of this is that of experiencing a melody, where it is essential to ability to have the experience that one is able to experience a series of notes, occurring in succession over a period of time, not as a durationless instant, but as an interval which is present. Although the first note of the melody has passed by the time it is experienced as part of the melody, it, along with the other notes, are experienced as present. It is an experience of succession, and not merely a succession of experiences. More generally, the phenomenon of the specious present seems to be required in order to explain how we can perceive such things as images on a TV screen or a computer's VDU, since light itself is motion, and has duration. When events are occurring so fast, we may not perceive the temporal order of them, and so we perceive them as simultaneous when they are not simultaneously presented to us in experience.

The specious present is said to be specious because it is experienced, not as durationless, but as an interval. The process involved in thinking about, and evaluating and adjusting one's own reasoning while continuing to engage in that reasoning described above might plausibly be viewed as one such case. ${ }^{22}$ Others are cases of reflective think-

\footnotetext{
${ }^{21}$ The concept of the specious present is due to the work of the psychologist E. R. Clay (quoted by James I 890) but its best known characterization is due to William James (I 890), who said, 'The prototype of all times is the specious present, the short duration of which we are immediately and incessantly sensible.' According to Le Poidevin (2004), current discussions of it tend to treat the specious present as 'the interval of time such that events within that interval are experienced as present. Taking the specious present as defined by this [third] characterization, the doctrine of the specious present holds that the group of events we experience at any one time as present contains successive events spanning an interval. The experienced present is "specious" in that, unlike the objective present, it is an interval and not a durationnless instant. The "real" present, as we might call it, must be durationless for, as Augustine argued, in any interval of any duration, there are earlier and later parts. So if any part of that interval is present, there will be another part that is past or future' (Le Poidevin 2004). If knowledge of one's own current conscious states is understood as taking place during an interval that involves a series of overlapping specious presents, then one's reflective state is reflecting on a state which is, during this interval past in 'real' terms. But what matters for the account is that it is experienced as present, and, as Le Poidevin points out, most states that are experienced as such are in the immediate past, and are so for good reasons (see Butterfield I984).

${ }^{22}$ I am not suggesting that the process of reasoning through an argument and critically evaluating one's reasoning might all occur during one specious present: even if the specious present is an interval of time rather than a durationless instant, such an interval could not plausibly encompass the amount of time it would take to engage in such a process of reasoning. What I am suggesting is that such a process and evaluation can occur in a series of overlapping specious presents, along the lines of the model Dainton (2000) gives.
} 
ing which involve self-ascriptions but are not truth-seeking and so do not count as cases of critical reasoning: in contemplating one's daydream of a picnic while fantasizing, for example, one may think reflectively about one's thoughts while suspending judgement on their truth. One might, even while continuing to fantasize, wonder why one is thinking of a picnic, why that situation is part of one's daydream.

\section{IV}

The Model. As I said, this idea can be further elaborated in terms of the idea of a subject's thinking, in reflection, a content that is partly type-identical to that which constitutes the thought reflected upon. First, there is the first-order thought, a subject's thinking that $p$, for some propositional content $p$. Then there is the second-order, reflective thought, that subject's thinking that she is thinking that $p$, in which, when all goes well, she thinks a token-distinct thought with a content that is partly type-identical with that which constitutes the first-order thought. She thinks that content again. How is 'aboutness' or reference to the first-order content, secured? One suggestion is that it is secured roughly in the way suggested by Davidson's paratactic analysis of sentences involving indirect discourse (Davidson I969). Suppose I think to myself, I am currently thinking that water is transparent. This second-order thought can be analysed as a compression or abbreviation of something like: I am currently thinking a thought whose content is the same as the following: water is transparent. When I think this thought, my thought is presented to me as having the same content as that of another current thought of mine-and my thought succeeds in this respect if (and only if) I am a samethinker with regard to these two thoughts (rather than a samesayer as in Davidson's original suggestion).

How is authority secured? When one is thinking about one's own conscious intentional state, one thinks a content of a type that can be known in an epistemically basic and direct way, and in this instance is known in that way. So the intellectual moves involved in recapturing an earlier train of thought no more involve a process of inference than do those involved in thinking cogito-type thoughts themselves. One either grasps the contents of the earlier states or one does not. If one does, it cannot be by thinking thoughts with different contents. So if one does, one grasps the contents of the ear- 
lier states with as much epistemic immediacy as one does in thinking the contents of the reflective states.

If one's interest in accounting for authoritative self-knowledge is motivated in part by the desire to provide a uniform general account of all such cases, then this would recommend a construal of the cogito-type cases that brings them more into line with others in recognizing the presence of a causal element and a first-order state distinct from and independent of the reflective one. An introspectionist account, based on the direct and immediate nature of a subject's knowledge of some of her own thoughts, can ground the asymmetry between self-knowledge and knowledge of others and explain why the former is genuinely authoritative despite being nonevidence-based. It can also ground an account, more generally, of authoritative self-knowledge of sensations and standing intentional states to whatever degree subjects possess it. But this does not mean that it can be defended in what many suppose to be the obvious way, namely, by appeal to some kind of 'inner sense' (cf. Armstrong I968, I98 I; Lycan I987, I996, 2004).

The point of the appeal to abstract and general features of observable properties of objects is to mark a distinction between what makes for direct epistemic access (the features of epistemic basicness, and epistemic directness or immediacy), on the one hand, and the medium by which subjects have direct epistemic access, on the other. In the perceptual case, it may be the phenomenological aspect of perceptual experience that makes for a subject's having direct epistemic access to the observable properties of objects of perception. However, in proprioception there is also direct and immediate awareness of the position of one's limbs, for example, and this is through no normal use of any medium of sense, so if there is a phenomenology associated with it, it is not of the same sort that attaches to perceptual experience. In introspection there is direct and immediate awareness of one's own thoughts, again through no normal use of any medium of sense. The source is cognitive, not sensory. But that should not prohibit the aptness of the analogy with observable properties of objects of perception, since that analogy appeals only to the features that make for direct epistemic access, and not to the medium by which subjects have it. ${ }^{23}$

${ }^{23}$ I have benefited greatly from comments from Eve Garrard, Graham Macdonald, and audiences at Trinity College Dublin, the University of Glasgow, and the 2008 Consciousness and Time workshop at the University of Edinburgh. 
School of Politics, International Studies and Philosophy Queen's University Belfast

2 I University Square Belfast BT7 IPA Northern Ireland

UK

\section{REFERENCES}

Alston, William P. I97I: 'Varieties of Privileged Access'. American Philosophical Quarterly, 8, pp. 223-4I.

Armstrong, D. M. 1981. 'What is Consciousness?'. In his The Nature of Mind and Other Essays, pp. 56-67. Ithaca, NY: Cornell University Press. Bar-On, Dorit 2004: Speaking My Mind: Expression and Self-Knowledge. Oxford: Oxford University Press.

Bermúdez, José Luis 1998: The Paradox of Self-Consciousness. Cambridge, MA: MIT Press.

Block, Ned 1995: 'On a Confusion about a Function of Consciousness'. Behavioral and Brain Sciences, I 8 (2), pp. 227-47.

- 2002: 'Some Concepts of Consciousness'. In David J. Chalmers (ed.), Philosophy of Mind: Classical and Contemporary Readings. Oxford: Oxford University Press, pp. 206-I8.

_2003: 'Mental Paint'. In Martin Hahn and Bjørn Ramberg (eds.), Reflections and Replies: Essays on the Philosophy of Tyler Burge, pp. I65200. Cambridge, MA: MIT Press.

-2005: 'Two Neural Correlates of Consciousness'. Trends in Cognitive Sciences, 9 (2), pp. 46-52. Longer version online at <http://www.nyu.edu/ gsas/dept/philo/faculty/block/papers/longerTiCS.pdf.

2007: 'Consciousness, Accessibility, and the Mesh between Psychology and Neuroscience'. Behavioral and Brain Sciences, 30, pp. 48I-500. 'Commentaries and Replies', pp. 500-48.

Brentano, Franz [1874] 1995: Psychology from an Empirical Standpoint, ed. Oskar Kraus and Linda L. McAlister, trans. A. C. Rancurelly, D. B. Terrell and L. L. McAlister. London: Routledge.

Burge, Tyler I988: 'Individualism and Self-Knowledge'. Journal of Philosophy, 85, pp. 649-63.

- 1996: 'Our Entitlement to Self-Knowledge'. Proceedings of the Aristotelian Society, 96, pp. 9I-I I6.

_ 1998: 'Memory and Self-Knowledge'. In Peter Ludlow and Norah Martin (eds.), Externalism and Self-Knowledge, pp. 35 I-70. Stanford, CA: CSLI Publications. 
2007: 'Reflections on Two Kinds of Consciousness'. In his Foundations of Mind: Philosophical Essays, Volume 2, pp. 392-4I9. Oxford: Oxford University Press.

Dainton, Barry 2000: Stream of Consciousness: Unity and Continuity in Conscious Experience. London: Routledge. Second edition, 2006.

Davidson, Donald I969: 'On Saying That'. Synthese, I9, pp. I30-46. Reprinted in Davidson I984b, pp. 93-108.

I I984a: 'First Person Authority'. Dialectica, 38, pp. IOI-I I. Reprinted in Davidson 200I, pp. 3-I4.

工 $1984 b$ : Inquiries into Truth and Interpretation. Oxford: Oxford University Press.

_ I987: 'Knowing One's Own Mind'. Proceedings and Addresses of the American Philosophical Association, 60, pp. 44I-58. Reprinted in Davidson 200I, pp. I 5-38.

-1989: 'What is Present to the Mind?'. In Johannes Brandl and Wolfgang Gombocz (eds.), Grazer Philosophische Studien, 36: The Mind of Donald Davidson, pp. 3-18. Reprinted in Davidson 200I, pp. 53-68.

-200I: Subjective, Intersubjective, Objective. Oxford: Clarendon Press.

Evans, Gareth 1982: The Varieties of Reference, ed. John McDowell. Oxford: Clarendon Press.

Gennaro, Rocco J. 2006: 'Between Pure Self-Referentialism and the (Extrinsic) HOT Theory of Consciousness'. In Uriah Kriegel and Kenneth Williford (eds.), Consciousness and Self-Reference, pp. 22 I-48. Cambridge, MA: MIT Press.

Gertler, Brie 2003: 'Self-Knowledge'. In Edward N. Zalta (ed.), The Stanford Encyclopedia of Philosophy (Spring 2003 Edition). <http://plato. stanford.edu/archives/spr2003/entries/self-knowledge/>

Hossack, Keith 2002: 'Self-knowledge and Consciousness'. Proceedings of the Aristotelian Society, I02, pp. I63-8I.

2003: 'Consciousness in Act and Action'. Phenomenology and the Cognitive Sciences, 2, pp. I 87-203.

Heil, John I988: 'Privileged Access'. Mind, 97, pp. 238-5I.

— I992: The Nature of True Minds. Cambridge: Cambridge University Press.

Husserl, Edmund [1928] 1964: Phenomenology of Internal Time-Consciousness, ed. Martin Heidegger, trans. James S. Churchill. Bloomington, IN: Indiana University Press.

James, William I 890: The Principles of Psychology. London: Macmillan.

Kriegel, Uriah 2003a: 'Consciousness as Intransitive Self-consciousness: Two Views and an Argument'. Canadian Journal of Philosophy, 33, pp. $103-32$.

$2003 b$ : 'Consciousness, Higher-Order Content, and the Individuation of Vehicles'. Synthese, I34, pp. 477-504. 
2004: 'Consciousness and Self-Consciousness'. Monist, 87, pp. I85209.

2005: 'Naturalizing Subjective Character'. Philosophy and Phenomenological Research, 7 I, pp. 23-57.

2006: 'The Same-Order Monitoring Theory of Consciousness, Second Version'. In Uriah Kriegel and Kenneth W. Williford (eds.), Self-Representational Approaches to Consciousness, pp. I43-70. Cambridge, MA: MIT Press.

Le Poidevin, Robin 2004: 'The Experience and Perception of Time'. In Edward N. Zalta (ed.), The Stanford Encyclopedia of Philosophy (Winter 2004 Edition). <http://plato.stanford.edu/archives/win2004/entries/timeexperience/>.

Lycan, William G. I987: Consciousness. Cambridge, MA: MIT Press.

I 1996: Consciousness and Experience. Cambridge, MA: MIT Press.

Macdonald, Cynthia I998a: 'Externalism and Authoritative Self-Knowledge'. In Crispin Wright, Barry C. Smith and Cynthia Macdonald (eds.), Knowing Our Own Minds, pp. I23-54. Oxford: Oxford University Press.

— I998b: 'Self-knowledge and the "Inner Eye". Philosophical Explorations, I, pp. 83-106.

-forthcoming: Self-Knowledge: Entitlement, Privilege, and Authority. Manuscript.

McDowell, John I986: 'Singular Thought and the Extent of Inner Space'. In Philip Pettit and John McDowell (eds.), Subject, Thought, and Context, pp. I37-68. Reprinted in John McDowell, Meaning, Language, and Reality, pp. 228-59. Cambridge, MA: Harvard University Press, I 998.

— I998: 'Response to Crispin Wright'. In Crispin Wright, Barry C. Smith and Cynthia Macdonald (eds.), Knowing Our Own Minds, pp. 47-62. Oxford: Oxford University Press.

McGeer, Victoria I996: 'Is "Self-Knowledge" an Empirical Problem? Renegotiating the Space of Philosophical Explanation'. Journal of Philosophy, 93, pp. 485-5I 5 .

Martin, M. G. F. I998: 'An Eye Directed Outward'. In Crispin Wright, Barry C. Smith and Cynthia Macdonald (eds.), Knowing Our Own Minds, pp. 99-I 2 I. Oxford: Oxford University Press.

Moran, Richard 2005: Authority and Estrangement: An Essay on SelfKnowledge. Princeton, NJ: Princeton University Press.

Rosenthal, David M. I986: 'Two Concepts of Consciousness'. Philosophical Studies, 49, pp. 329-59.

_ I997: 'A Theory of Consciousness'. In Ned Block, Owen Flanagan and Güven Güzeldere (eds.), The Nature of Consciousness: Philosophical Debates, pp. 729-53. Cambridge, MA: MIT Press.

2005: Consciousness and Mind. Oxford: Oxford University Press. 
Shoemaker, Sydney 1968: 'Self Reference and Self Awareness'. Journal of Philosophy, 65, pp. 555-67.

Smith, David Woodruff I986: 'The Structure of (Self-)Consciousness'. Topoi, 5, pp. I49-56.

_ I989: The Circle of Acquaintance. Dordrecht: Kluwer Academic Publishers.

Sosa, Ernest 2003: 'Privileged Access'. In Quentin Smith and Aleksandar Jokic (eds.), Consciousness: New Philosophical Perspectives, pp. 27394. Oxford: Oxford University Press.

Thomasson, Amie L. 2000: 'After Brentano: A One-Level Theory of Consciousness'. European Journal of Philosophy, 8(2), pp. I90-209.

Williford, Kenneth 2006: 'The Self-Representational Structure of Consciousness'. In Uriah Kriegel and Kenneth Williford (eds.), Self-Representational Approaches to Consciousness, pp. III-42. Cambridge, MA: MIT Press.

Wright, Crispin I986: 'On Making Up One’s Mind: Wittgenstein on Intention'. In P. Weingartner and G. Schurz (eds.), Logic, Philosophy of Science and Epistemology: Proceedings of the Eleventh International Wittgenstein Symposium, pp. 39 I-404. Vienna: Holder-Pickler-Tempsky. _ I988: 'Moral Values, Projection and Secondary Qualities'. Proceedings of the Aristotelian Society Supplementary Volume 62, pp. I-26.

_ I989: 'Wittgenstein's Later Philosophy of Mind: Sensation, Privacy, and Intention'. Journal of Philosophy, 86, pp. 622-34.

- I992: Truth and Objectivity. Cambridge, MA: Harvard University Press.

— 1998: 'Self-Knowledge: The Wittgensteinian Legacy'. In Crispin Wright, Barry C. Smith and Cynthia Macdonald (eds.), Knowing Our Own Minds, pp. 13-46. Oxford: Oxford University Press.

Zahavi, Dan I998: 'Brentano and Husserl on Self-Awareness'. Études Phénoménologiques, 27-28, pp. I27-68.

2006: 'Two Takes on a One-Level Theory of Consciousness'. Psyche, I2 (2). <http://psyche.cs.monash.edu.au/symposia/kriegel/4Zahavi.pdf> 